\title{
Aging Characteristics of Elastic Duplicating Compounds
}

\author{
R. G. CRAIG, P. E. GEHRING, and F. A. PEYTON \\ University of Michigan, School of Dentistry, Ann Arbor, Michigan
}

One of the principal differences between the use of agar duplicating compounds compared with agar impression materials is that the duplicating compounds are subjected to repeated heating and gelation cycles and also to extended storage at temperatures from $125^{\circ}$ to $150^{\circ} \mathrm{F}$. The change in physical properties of duplicating compounds with use or aging is, therefore, of particular interest in an evaluation of these materials.

The changes on heating and storage of one commercial agar-type duplication compound and an experimental 5 per cent agar material were determined by Margetis and Hansen. ${ }^{1}$ The properties selected for this evaluation were changes in $\mathrm{pH}$, viscosity, and crushing time. The $\mathrm{pH}$ and crushing time decreased during heating and storage of the agar compounds for 32 days. The viscosity of the agar sols decreased slightly after repeated heating and cooling cycles. On storage of the agar compounds at elevated temperatures, the viscosity tended either gradually to increase or to increase after an initial decrease, probably as a result of slow partial gelation of the agar.

The properties of duplicating and impression compounds, as influenced by storage for 3 days at elevated temperatures and by 12 boiling and cooling cycles were recently reported by Duke and Ryge. ${ }^{2}$ The tests used in this study were those described in the A.D.A. Specification No. 11 for Hydrocolloid Impression Material-Agar Type. ${ }^{3}$ The limited control of the water content of the agar duplicating compounds during the repeated heating and gelation cycles appeared to have a pronounced effect on the per cent strain in compression and the per cent permanent set values. Little change was observed in the per cent strain in compression and the per cent permanent set after storage for 3 days at $155^{\circ} \mathrm{F}$. Duplicating compounds, however, are often stored for 30 days or more at elevated temperatures, and the lack of change in physical properties after 3 days' storage represents a limited evaluation of the stability of the duplicating compound.

The first purpose of this study was to evaluate the changes in physical properties as a result of aging changes in a number of commercial duplicating compounds after storage at elevated temperatures for periods up to 60 days and after repeated boiling and cooling cycles under carefully controlled conditions to prevent changes in the water content of the duplicating compounds.

The second purpose of the study was to examine the effect of secondary components and manipulative variables on the aging changes of agar duplicating compounds. The components normally present in agar compounds and possible impurities present as a

This report represents the partial results of studies supported by contract No. DA-49-007-MD-938 between the Office of the Surgeon General, Department of Army, and the University of Michigan.

Received for publication July $24,1961$. 
result of the duplication procedure were added to experimental agar compounds, in order to establish their effect on the aging of these materials. The effect of manipulative variables, such as grinding of the agar gels and ultrasonic treatment of the agar sols, on the physical properties of duplicating compounds was also investigated.

\section{MATERIALS AND METHODS}

The commercial duplicating compounds used in this study are listed in Table 1, with a corresponding code letter, batch number, and manufacturer. All materials were of the agar-base type except material $\mathbf{B}$, which was a reversible plastic gel. The materials were prepared for use and manipulated according to the manufacturers' instructions.

Experimental agar compounds were prepared from a dental-grade American agar in the following manner. The dry agar was soaked overnight in water contained in a sealed Mason jar. The soaked agar in the sealed jar was then heated in a boiling

TABLE 1

MATERIALS, BATCH NUMBERS, AND MANUfACTURERS

\begin{tabular}{|c|c|c|c|}
\hline $\begin{array}{c}\text { Code } \\
\text { Letter }\end{array}$ & Material & $\begin{array}{l}\text { Batch No. } \\
\text { or Date }\end{array}$ & Manufacturer \\
\hline $\begin{array}{l}\text { A } \ldots \ldots \\
\text { B } \ldots \ldots \\
\text { C. } \ldots \ldots \\
\text { D. } \ldots \ldots \\
\text { E. } \ldots \ldots \\
\text { G. } \ldots \ldots \\
\text { H. . . . }\end{array}$ & $\begin{array}{l}\text { Copymaster } \\
\text { Lastic } \\
\text { Multigel } \\
\text { Nobiloid } \\
\text { Perflex } \\
\text { Surgident } \\
\text { Ticonium Special } \\
\text { Van R }\end{array}$ & $\begin{array}{c}102150 \\
3-9-60 \\
\text { OFF } \\
\text { D1, PP3 } \\
060077 \\
20560,10660 \\
5442,5458 \\
007628\end{array}$ & $\begin{array}{l}\text { L. D. Caulk Company } \\
\text { Durallium Products Corporation } \\
\text { Ransom and Randolph Co. } \\
\text { Nobilium Products, Inc. } \\
\text { Austenal, Inc. } \\
\text { Surgident, Ltd. } \\
\text { Dental Perfection Company } \\
\text { Walter J. van Rossem }\end{array}$ \\
\hline
\end{tabular}

water bath for 1 hour, in order to prepare a homogeneous sol. Borax, potassium sulfate, or preservatives ( $n$-methyl or $n$-propyl $p$-hydroxybenzoate) were added, if desired, to the agar sol in the proper concentrations. The agar concentration of the sols was 8 per cent by weight.

The repeated heating and gelation experiments were conducted by placing the properly diluted materials in sealed Mason jars and heating them in boiling water for 1 hour. The agar sols were cooled to $130^{\circ} \mathrm{F}$., and specimens were poured at this temperature. The specimens were discarded after being tested because they would have altered the water content of the material in the jar. The remaining material in the sealed jar was allowed to cool to room temperature, and the gel was stored at that temperature until the next day, when the above cycle was repeated.

The agar compounds to be stored at elevated temperatures were also placed in sealed Mason jars. After an initial heating, in order to produce a sol, they were stored in a constant-temperature oven at a temperature of $135^{\circ} \mathrm{F}$. or $150^{\circ} \mathrm{F}$. Specimens were prepared by removing sufficient sol from the sealed jar; this material was poured into the specimen molds. Sufficient duplicating material was stored so that samples could be taken at frequent intervals for periods up to 60 days.

The preparation of specimens and methods used to determine the compressive strength, per cent set after 12 per cent strain, crushing time, and tear strength have 
previously been described. ${ }^{4}$ It was observed that the specimens used for the crushingtime test needed to be prepared under a very rigidly defined set of conditions, in order to obtain consistent results. The length of time the agar compound was heated, the temperature of pouring the specimens, and the length of time and conditions under which the specimens were stored had to be controlled. The heating time was 1 hour, the pouring temperature was $130^{\circ} \mathrm{F}$, and the samples were removed from the molds after $\frac{1}{2}$ hour and were stored in a desiccator at 100 per cent relative humidity an additional $\frac{1}{2}$ hour before they were tested.

The effect of the temperature of pouring on the crushing time is shown in Table 2 . The crushing time increased as the temperature of pouring decreased from $180^{\circ}$ to $135^{\circ} \mathrm{F}$. Specimens poured at temperatures between $135^{\circ}$ and $120^{\circ} \mathrm{F}$. gave essentially the same crushing-time values. The temperature of $130^{\circ} \mathrm{F}$. was selected on the basis of these results and the consistency of the sols at this temperature.

TABLE 2

Effect of Pouring Temperature on the Crushing Time OF 8 PER CENT AMERICAN AGAR GeLS

\begin{tabular}{|c|c|c|c|c|c|}
\hline $\begin{array}{l}\text { Pouring Temperature } \\
\qquad\left({ }^{\circ} \mathrm{F} .\right)\end{array}$ & $\begin{array}{c}\text { Crushing Time* } \\
\text { (Seconds) }\end{array}$ & $\begin{array}{l}\text { Pouring Temperature } \\
\qquad\left({ }^{\circ} \mathrm{F} .\right)\end{array}$ & $\begin{array}{c}\text { Crushing Time* } \\
\text { (Seconds) }\end{array}$ & $\begin{array}{c}\text { Pouring Temperature } \\
\left({ }^{\circ} \mathrm{F} .\right)\end{array}$ & $\begin{array}{l}\text { Crushing Time* } \\
\text { (Seconds) }\end{array}$ \\
\hline $\begin{array}{l}120 \ldots \ldots \ldots \ldots \\
125 \ldots \ldots \ldots \ldots \\
130 \ldots \ldots \ldots \ldots\end{array}$ & $\begin{array}{l}65 \\
69 \\
66\end{array}$ & $\begin{array}{l}135 . \\
140 . \\
150 .\end{array}$ & $\begin{array}{l}64 \\
55 \\
46\end{array}$ & $\begin{array}{l}160 \ldots \ldots \\
170 \ldots \ldots \\
180 \ldots \ldots\end{array}$ & $\begin{array}{l}46 \\
46 \\
35\end{array}$ \\
\hline
\end{tabular}

* $18.0 \mathrm{lb} /$ in $^{2}$ stress applied to cylindrical specimens.

\section{RESULTS}

In order to relate laboratory results with actual use of duplicating materials, the physical properties of agar duplicating compound $\mathrm{G}$ were tested after various periods under conditions of actual dental laboratory usage. The per cent set, compressive strength, tear strength, and crushing time were determined and plotted against the number of cases processed, as shown in Figure 1. The duplicating compound was stored at $135^{\circ} \mathrm{F}$, and the surface of the material in contact with the investment cast was washed before reboiling and replacing it in the storage container. It can be seen that the per cent set, compressive-strength, and tear-strength values remained relatively constant until approximately 60 cases had been processed. After this time, the per cent set increased, and the compressive strength and tear strengths decreased up to the end of the testing period of 110 cases. The testing period covered 35 days of storage at $135^{\circ} \mathrm{F}$. The changes in these properties are indicative of degradation of the elastic properties of the duplicating compound.

The crushing-time values, however, decreased gradually from an initial value of 28 seconds to 5 seconds after 110 cases and 35 days' storage at $135^{\circ} \mathrm{F}$. Since the crushing-time test measures a combination of elasticity and flow, these results indicated that there was a gradual change in the viscoelastic properties of the agar duplicating compound when subjected to a combination of repeated heating and gelation cycles and storage at elevated temperatures. The curves in Figure 1 illustrate that the crushing-time test was the most sensitive of the four tests for detecting changes as 
a result of aging by heating. The crushing-time test, therefore, was selected to evaluate the changes in agar duplicating compounds under various conditions of aging. It should be noted that duplicating compound $G$ was found to function satisfactorily until a crushing time of 5 seconds was observed, and a safe limit would appear to be approximately 10 seconds.

The effect of reboiling on the crushing time of a number of duplicating compounds is presented in Figure 2. An examination of Figure 2 reveals the main difficulty observed with the crushing-time test. It was not possible to test all duplicating compounds with the same stress applied to the specimens, since the range was too large.

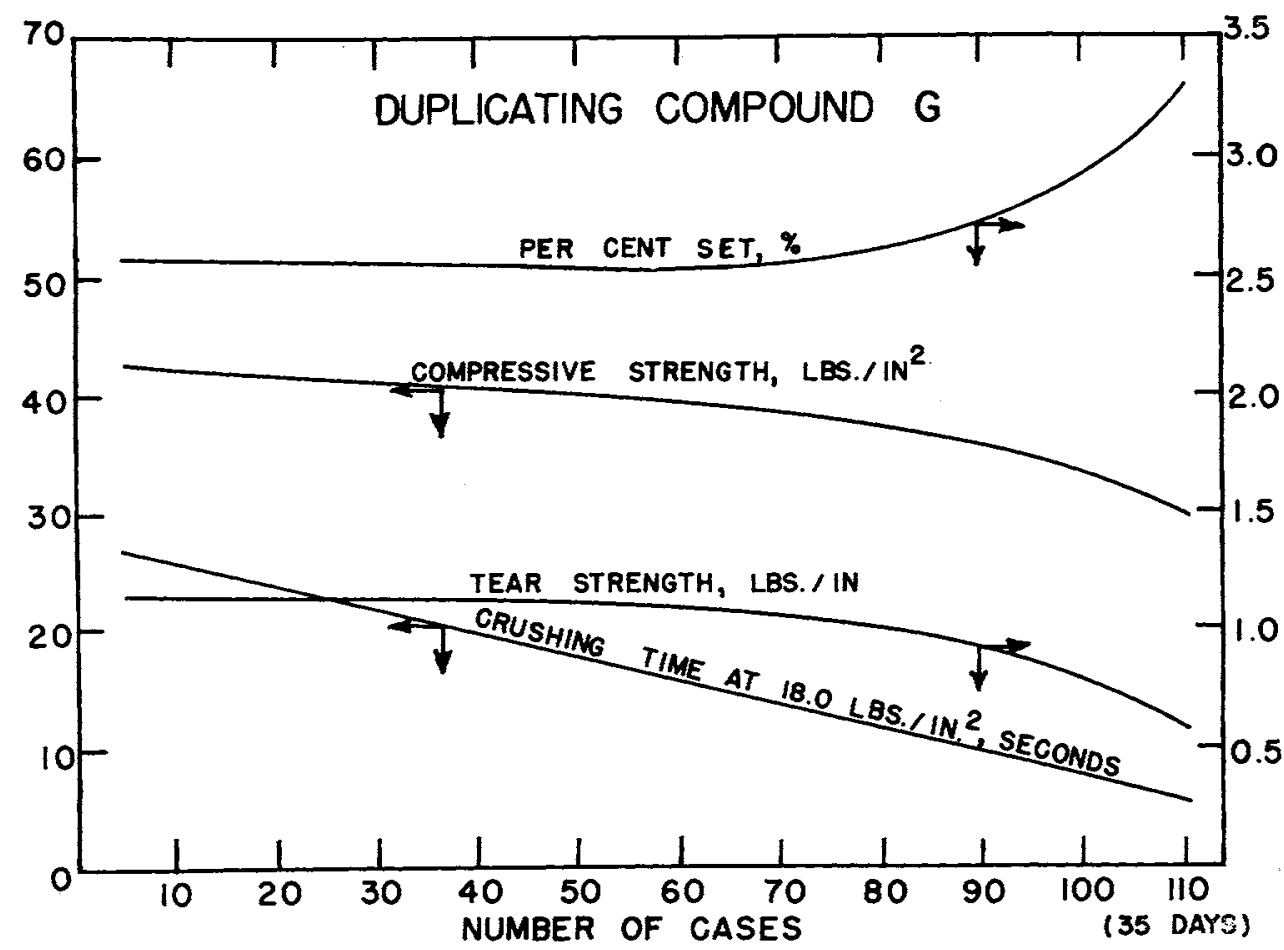

Fig. 1.-Change in physical properties of an agar duplicating compound during use by a dental laboratory.

For example, compound E could withstand a stress of $12.4 \mathrm{lb} / \mathrm{in}^{2}$ for almost an indefinite period of time. In order to obtain reasonable values, it was necessary to apply a stress of $31.0 \mathrm{lb} / \mathrm{in}^{2}$ to specimens of compound $\mathrm{E}$, and only after 19 reboilings had the material become sufficiently degraded to be tested at a stress of $18.0 \mathrm{lb} / \mathrm{in}^{2}$. The crushing time for the various products at any given number of reboiling cyles should be considered together with the stress applied to the test specimen in an evaluation of the aging of a series of duplicating compounds.

The crushing time of the agar duplicating compounds generally decreased as the number of reboiling cycles increased. Compound $\mathbf{H}$ was an exception, in that the crushing time increased from 70 to 90 seconds between the first and fifth cycle, after which time the crushing time decreased with the number of reboiling cycles in a normal 
manner. This behavior of compound $\mathrm{H}$ was not an intermittent result and has been reproduced on numerous runs with several different batches of this agar duplicating compound. The curves representing the crushing time versus reboiling cycles were characterized by an initial rather rapid decrease in the crushing time until approximately 7 reboiling cycles had been reached. From the seventh reboiling cycle until the end of the test period the crushing time usually decreased at a more gradual rate. The single exception to this generalization was compound $\mathrm{D}$, which showed a break in the curve at about the seventh reboiling cycle but after the ninth cycle the crushing time values decreased at the original rate.

The curves in Figure 2 illustrate that an initially high value for the crushing time is a general indication that superior values will be obtained after repeated reboiling cycles. This was not true for compounds $A$ and $F$, which had essentially the same initial crushing-time values at a stress of $18.0 \mathrm{lb} / \mathrm{in}^{2}$, but compound $\mathrm{A}$ had a crushing time of only 10 seconds after 19 reboiling cycles and compound $F$ had a much higher value of 46 seconds after the same number of cycles.

The effect of storage of agar duplicating compounds at $135^{\circ} \mathrm{F}$. on the crushing time is shown in Figure 3. For all the duplicating compounds except one, a gradual decrease was observed in the crushing time as the storage time increased. Duplicating compound $\mathrm{H}$ was again unusual, in that the crushing time increased from an original value of 45 seconds to 54 seconds after being stored 7 days at $135^{\circ}$ F. From 7 days until the end of the storage test at 60 days, the crushing time of compound $\mathrm{H}$ gradually decreased. Duplicating compound $\mathrm{D}$, however, in spite of its high original crushing time, indicated a more rapid change in the viscoelastic properties than the other duplicating compounds by the more rapid decrease of the crushing time with storage at $135^{\circ} \mathrm{F}$.

It was found to be impractical to study the aging of duplicating compounds $\mathrm{A}$ and $\mathrm{F}$ when stored at $135^{\circ} \mathrm{F}$. because of partial gelation of the sol during the extended storage periods. The aging of these compounds was carried out at a storage temperature of $150^{\circ} \mathrm{F}$. (see Fig. 4). At this temperature the duplicating compounds remained in the sol state during the test period of 7 weeks. For purposes of comparison, the aging of duplicating compound $\mathrm{G}$ was also evaluated at $150^{\circ} \mathrm{F}$. The crushing time of duplicating compounds $A, F$, and $G$ decreased rapidly for the first 5 days of storage at $150^{\circ} \mathrm{F}$, but for times longer than 1 week the decrease was much more gradual. Storage at $150^{\circ} \mathrm{F}$. was much more detrimental to duplicating compound $\mathrm{G}$ than storage at $135^{\circ} \mathrm{F}$. For example, the crushing times after 7 days' storage at $150^{\circ}$ and $135^{\circ} \mathrm{F}$. were 17 and 42 seconds, respectively.

The aging of duplicating compound $\mathrm{B}$-the reversible plastic gel-was best assessed by changes in the compressive strength after various storage times at the recommended temperature of $210^{\circ} \mathrm{F}$. The manufacturer's constant-temperature automatic dispenser was used throughout the aging experiments to store the duplicating compound. The compressive strength of the specimens was determined as previously reported. ${ }^{4}$ The effect of continuous storage of compound $\mathrm{B}$ at $210^{\circ} \mathrm{F}$. on the compressive strength is shown in Table 3 . The compressive strength decreased from an original value of $145 \mathrm{lb} / \mathrm{in}^{2}$ to $115 \mathrm{lb} / \mathrm{in}^{2}$ after 80 days of storage at $210^{\circ} \mathrm{F}$. This material continued to degrade slowly and had a compressive strength of $105 \mathrm{lb} / \mathrm{in}^{2}$ after 140 days of storage at $210^{\circ} \mathrm{F}$. The aging of duplicating compound $\mathrm{B}$ was accompanied by a grad- 


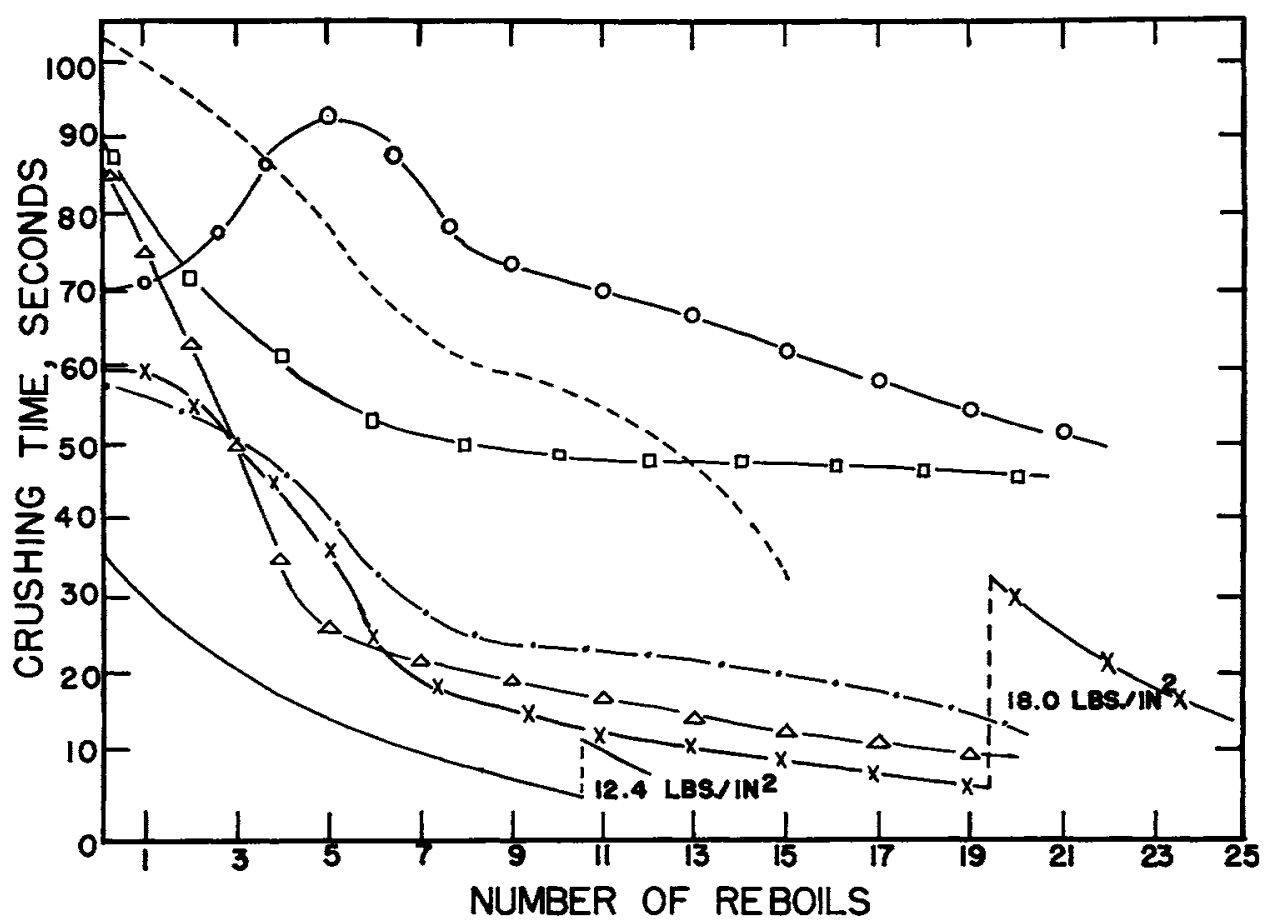

Fig. 2.-Effect of reboiling on the crushing time of agar duplicating compounds. Duplicating compounds: $A:-\triangle \longrightarrow, 18.0 \mathrm{Ib} / \mathrm{in}^{2} ; C: \longrightarrow, 18.0$ stress; $D:--, 18.0 ; E:-\mathrm{X}-, 31.0$; $F:-\square-, 18.0 ; G:-\cdot-, 12.4 ; H:-0-12.4$.

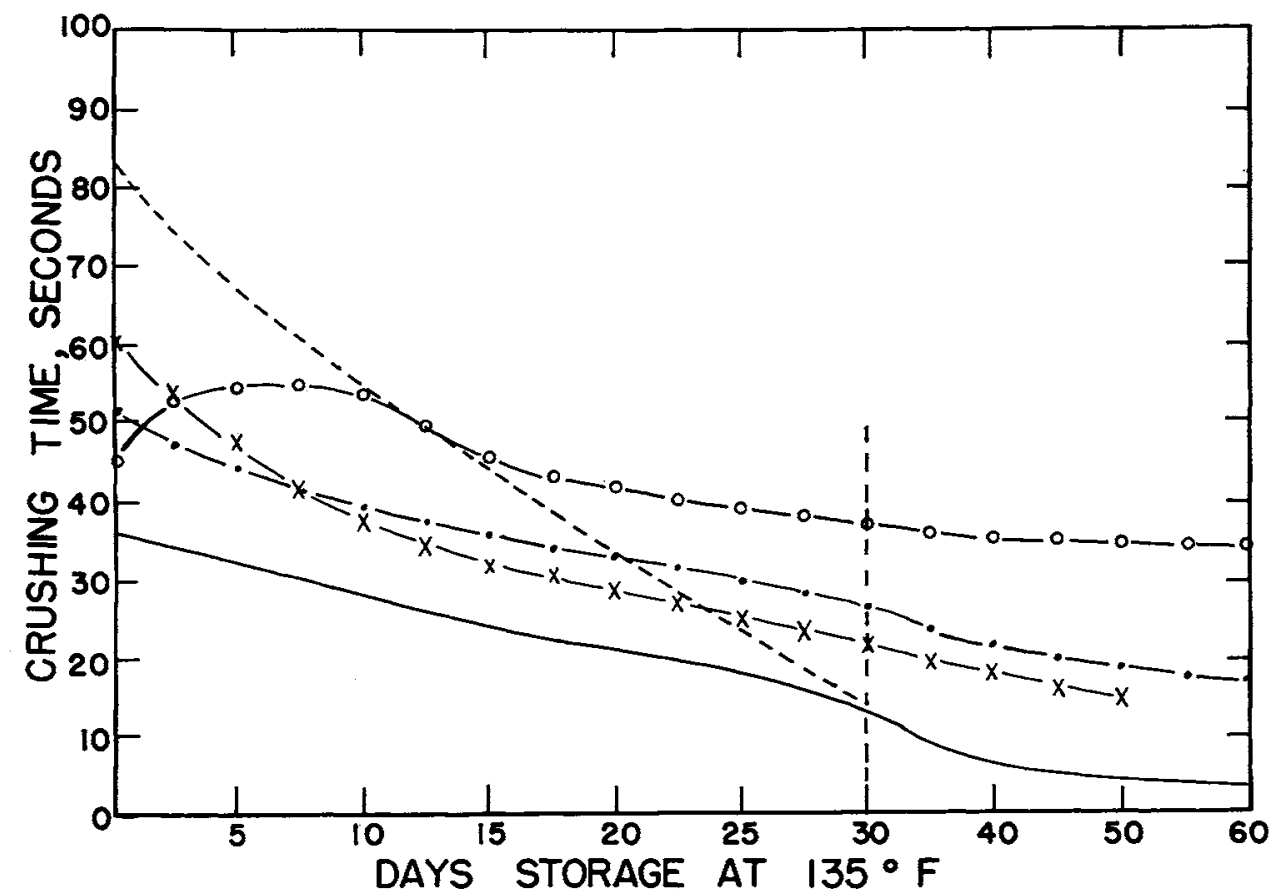

Frc. 3.-Effect of storage at $135^{\circ} \mathrm{F}$. on the crushing time of agar duplicating compounds. Duplicating compounds: $C:-, 18.0 \mathrm{lb} /$ in $^{2}$ stress; $D:---, 18.0 ; E:-\times-, 31.0 ; G:--, 12.4$; 
ual darkening of the material as a result of carbonaceous products and an increased tendency for the material to adhere to stone casts.

The effect of borax on the aging of an experimental agar duplicating compound is shown in Table 4. An 8 per cent agar sol was prepared, and to half of the sol 0.1 per cent by weight of borax was added, the remaining half of the sol being used as a control. After the first reboiling of the experimental duplicating compound, the crushing time of the gel containing borax was 94 seconds, compared with a value of 22 seconds for the control sample. This marked improvement in the viscoelastic properties of agar gels has been indicated in studies relating the compressive strength of the agar gels to the borax concentration. ${ }^{5}$ Of particular interest were the crushing-time

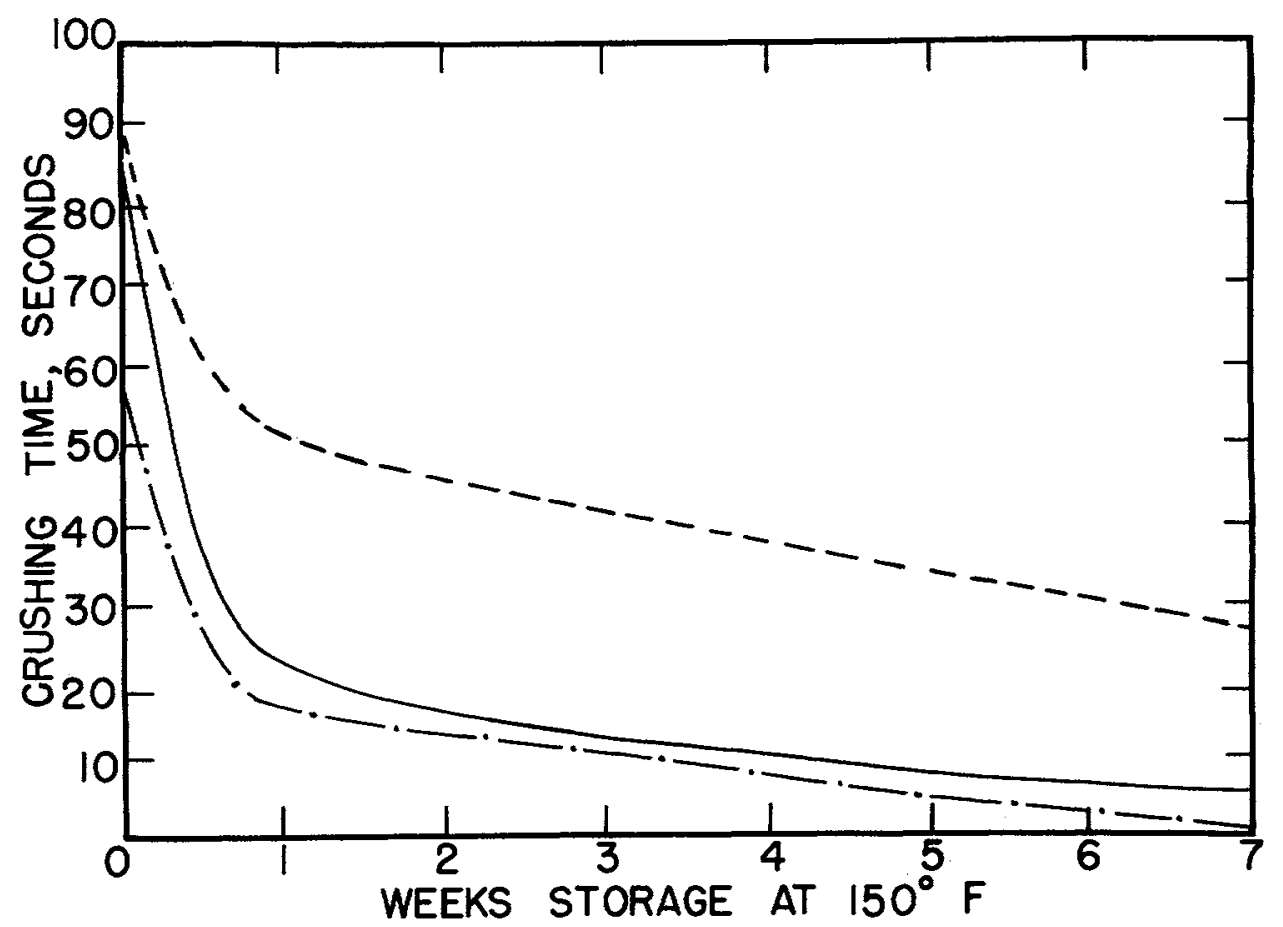

Fic. 4.-Effect of storage at $150^{\circ} \mathrm{F}$. on the crushing time of agar duplicating compounds. Duplicat-

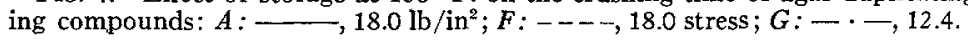

TABLE 3

Aging of Duplicating Compound B Stored at $210^{\circ} \mathrm{F}$.

\begin{tabular}{|c|c|c|c|}
\hline $\begin{array}{l}\text { Aging Time } \\
\text { (Days) }\end{array}$ & $\begin{array}{c}\text { Compressive } \\
\text { Strength* } \\
\left(\mathrm{Lb} / \mathrm{In}^{2}\right)\end{array}$ & $\begin{array}{c}\text { Aging Time } \\
\text { (Days) }\end{array}$ & $\begin{array}{c}\text { Compressive } \\
\text { Strength* } \\
\left(\mathrm{L} b / \mathrm{In}^{2}\right)\end{array}$ \\
\hline 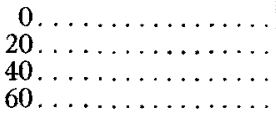 & $\begin{array}{l}145 \\
134 \\
126 \\
120\end{array}$ & $\begin{array}{r}80 \ldots \ldots \ldots \\
100 \ldots \ldots \ldots \ldots \\
120 \ldots \ldots \ldots \\
140 \ldots \ldots \ldots\end{array}$ & $\begin{array}{l}115 \\
111 \\
108 \\
105\end{array}$ \\
\hline
\end{tabular}

* Determined at a deformation rate of 10 inches/minute. 
values of the gels containing borax and the control after being subjected to numerous reboiling cycles. The crushing time of the control decreased about 2 seconds per reboiling cycle until the eighth cycle, after which it decreased only 0.5 second per cycle. The samples containing borax also had crushing times that decreased more rapidly during the first eight reboiling cycles than from the eighth to the twentieth cycle. At comparable reboiling cycles, however, the crushing times of the samples containing borax, in all cases, were substantially higher than the control samples.

The addition of $\mathrm{K}_{2} \mathrm{SO}_{4}$ in amounts up to 2 per cent by weight did not result in any measurable difference in the original values for the crushing time or the decrease in crushing time with aging by the reboiling procedure. Likewise, the presence of 0.05 per cent $n$-propyl $p$-hydroxybenzoate or 0.08 per cent of $n$-methyl $p$-hydroxybenzoate did not alter the values for the time of crushing.

TABLE 4

EFFECT OF BORAX ON CRUSHING TIME AND AgING OF 8 PER CENT AMERICAN AGAR

\begin{tabular}{|c|c|c|c|c|c|}
\hline $\begin{array}{l}\text { Number of } \\
\text { Reboils }\end{array}$ & $\begin{array}{c}\text { Crushing Time* } \\
\text { of Control } \\
\text { (Seconds) }\end{array}$ & $\begin{array}{l}\text { Crushing Time* } \\
\text { of Gels Con- } \\
\text { taining Borax } † \\
\text { (Seconds) }\end{array}$ & $\begin{array}{c}\text { Number of } \\
\text { Reboils }\end{array}$ & $\begin{array}{l}\text { Crushing Time* } \\
\text { of Control } \\
\text { (Seconds) }\end{array}$ & $\begin{array}{l}\text { Crushing Time* } \\
\text { of Gels Con- } \\
\text { taining Borax } 1 \\
\text { (Seconds) }\end{array}$ \\
\hline $\begin{array}{l}1 \ldots \ldots \\
2 \ldots \ldots \\
3 \ldots \ldots \\
4 \ldots \ldots \\
5 \ldots \ldots \\
6 \ldots \ldots \\
7 \ldots \ldots\end{array}$ & $\begin{array}{l}22 \\
19 \\
17 \\
15 \\
13 \\
11 \\
10\end{array}$ & $\begin{array}{l}94 \\
90 \\
84 \\
75 \\
65 \\
55 \\
44\end{array}$ & $\begin{array}{r}8 \ldots \ldots \ldots \\
10 \ldots \ldots \\
12 \ldots \ldots \\
14 \ldots \ldots \\
16 \ldots \ldots \\
18 \ldots \ldots \\
20 \ldots \ldots\end{array}$ & $\begin{array}{l}8 \\
6 \\
5 \\
4 \\
3 \\
2 \\
2\end{array}$ & $\begin{array}{l}36 \\
29 \\
26 \\
24 \\
24 \\
25 \\
24\end{array}$ \\
\hline
\end{tabular}

* $18.0 \mathrm{lb} / \mathrm{in}^{2}$ stress applied to cylindrical specimens.

$\dagger$ Borax concentration of 0.1 weight per cent was used.

The presence of $\mathrm{CaSO}_{4}$ in the agar sols, in amounts necessary to produce a saturated water solution, did not have any measurable effect on the viscoelastic or aging properties of the agar gels prepared from these sols. Ten times the saturation value of $\mathrm{CaSO}_{4}$, however, produced a reduction in the crushing time of 8 per cent agar gels, compared with the controls after more than 5 reboiling cycles. For example, after the eighth reboiling cycle, an agar gel containing no $\mathrm{CaSO}_{4}$ or the saturation amount would have a crushing time of 105 seconds and the gel containing ten times the saturation amount of $\mathrm{CaSO}_{4}$ would have a value of only 70 seconds.

The effect of particles of set gypsum-bonded investment in agar gels substantiated the results of the previous measurements. Duplicating compound $G$ was used under dental laboratory conditions. The duplicating material was divided in half and each portion stored in a separate conditioner. Duplicate gypsum-bonded investment casts were prepared, using the duplicating compound from one of the two conditioners. The duplicating compound from the first conditioner was rinsed with water after the duplication procedure, in order to remove any investment particles adhering to the surface, and was then reboiled and returned to the conditioner. The duplicating compound from the second conditioner was not rinsed after the removal of the investment cast but was reboiled and added to the material in the conditioner. The number 
of reboiling cycles and the number of cases were recorded, and the corresponding crushing times were determined. When the duplicating compound was not rinsed, the crushing time was 10 seconds after 106 duplications, but when it was rinsed, the crushing time was 15 seconds after 146 duplications.

There was some question regarding the use of a mechanical device to grind up the agar duplicating gel in preparation for converting it to a sol. Duplicating compound $\mathrm{G}$ was ground up using a hand-driven meat grinder and was then heated to convert it to the sol state. Samples were prepared and the crushing times were determined. These results were compared with those from duplicating compound $G$, which was cut up with a knife in preparation for reboiling. It was found, when care was taken to avoid the loss of liquid during the grinding of the agar gel, that no degradation of the material was observed compared with the agar gel which was cut up.

Since agglomeration of portions of the agar appeared to take place during extended reboiling and storage at elevated temperatures, it was felt that possibly ultrasonic treatment of the agar sols might produce some dispersion of the agglomerates and thus extend the useful life of the agar duplicating materials. After each reboiling of the agar duplicating compounds the hot sol was vibrated at 90,000 cycles per second for 5 minutes. This ultrasonic treatment produced a variety of results. The first series of tests showed that the crushing time of the ultrasonically treated duplicating compound did not decrease nearly so rapidly as the control. Further tests revealed that no change or degradation could be observed after the ultrasonic treatment. The cause of these variable results has not as yet been established.

\section{DISCUSSION}

The per cent set values in the present investigation were found to be quite insensitive to numerous reboiling cycles and to reasonably long storage times at temperatures of $135^{\circ} \mathrm{F}$. Variations in the per cent set values reported by Duke and Ryge, ${ }^{2}$ such as $2.2,3.2,4.9$, and 2.9 per cent for $1,2,6$, and 12 reboiling cycles, respectively, were possibly the result of variations in the water content rather than aging of the duplicating compounds. The variation in water content is also the possible reason for the variations in their strain in compression measurements. If the duplicating compounds were subjected to sufficient reboiling cycles, usually 15 or more, the per cent set began to increase in a regular manner, indicating aging changes. Little change was observed in the per cent set values by Duke and Ryge ${ }^{2}$ in their storage tests of 72 hours. This result would be expected on the basis of current measurements, since little change was observed in this property until after 4-6 weeks' storage at $150^{\circ} \mathrm{F}$.

The results of the crushing time tests were in agreement with those of Margetis and Hansen, ${ }^{1}$ who showed that the values were a direct function of the aging of the duplicating compounds accomplished by reboiling or storing at elevated temperatures. The plots of the crushing times versus number of reboiling cycles for the various duplicating compounds suggested that two mechanisms may be involved in the degradation of the viscoelastic properties. The initial rapid decrease in the crushing-time values may represent hydrolysis of the agar, while the latter, more gradual decrease may result from agglomeration of the agar micelles. Possible support of this idea is found in the unusual behavior of duplicating compound $\mathrm{H}$. This particular material contains small amounts of base to react with residual amounts of acid adsorbed on 
the agar from the bleaching operation. The presence of the base may retard the hydrolysis of the agar and thus aid in retarding the degradation. Also the strength of agar gels are higher under alkaline than acid conditions, ${ }^{6}$ which may account for the small increase in crushing time during the early stages of the aging of duplicating compound $\mathrm{H}$.

A comparison of the crushing times after daily reboiling and storage at $135^{\circ} \mathrm{F}$. illustrates that reboiling the duplicating compounds, in general, caused more degradation than did storage in the sol state at $135^{\circ} \mathrm{F}$. Daily reboiling of the agar duplicating compounds, however, appeared to degrade the materials about the same amount as did continuous storage at $150^{\circ} \mathrm{F}$. These data would favor the preparation of a duplicating compound that could be stored for extended periods at $135^{\circ} \mathrm{F}$. without the occurrence of noticeable amounts of gelation.

The effect of adding various chemical compounds to the agar materials indicated that borax had a beneficial effect on the strength of the aged agar duplicating compounds. The presence of $\mathrm{K}_{2} \mathrm{SO}_{4}$ or preservatives of the benzoate type did not alter the properties of the agar compound, but several commercial duplicating compounds could use more adequate protection against the growth of molds.

The presence of $\mathrm{CaSO}_{4}$ accelerated the aging of the agar only after 5 or more reboiling cycles. Since the micelles in the agar sol are negatively charged, ${ }^{5}$ the presence of excess amounts of a polyvalent cation such as $\mathrm{Ca}^{++}$and dehydrating anion such as $\mathrm{SO}_{4}^{-}$would cause the lyophilic sol to become unstable and agglomerate. This agglomeration would result in lower strength properties. The effect of excess $\mathrm{CaSO}_{4}$ on the aging of agar is also indirect evidence that the gradual decrease in the crushing-time values after the initial rapid decrease may be due mainly to agglomeration. In any case, these data indicate that the investment adhering to the agar duplicating material should be washed off prior to reboiling the agar compound in order to prolong the useful life of these materials.

The shearing and compression of the agar gel that took place during the grinding of the gels did not have any measurable effect on the resulting physical properties. The important feature in the grinding of agar gels was that some of the liquid phase held in the fibril network was squeezed out. If grinding is used to subdivide large pieces of agar gels, this liquid must be collected with the subdivided gel, in order to maintain the physical properties of the gels.

The brief study of the effect of ultrasonics on the aging of agar duplicating compounds produced variable results for several possible reasons. Several different batches of agar were used which may have had considerably different micellar structures in the sol state and thus were more or less susceptible to ultrasonic treatment. Also, variations in the rate of hydrolysis of the different agar materials would have masked the effect of dispersion of the agglomerates. Further efforts in this area would appear to be profitable.

\section{SUMMARY}

The changes in physical properties, or aging, of agar duplicating materials when subjected to reboiling cycles and to extended storage at temperatures of $135^{\circ}$ and $150^{\circ} \mathrm{F}$. were determined.

The compressive strength, tear strength, and per cent set values generally were stable for $15-20$ reboiling cycles or for storage at $150^{\circ} \mathrm{F}$. of $4-6$ weeks. 
The crushing-time test was more sensitive to small changes in the viscoelastic properties of the agar gels, and aging changes could be detected with this test after only 1 reboiling cycle.

The aging of agar gels appeared to take place in two stages, an initial rapid change followed by or accompanied by a much more gradual change in viscoelastic properties.

Storage at $135^{\circ} \mathrm{F}$. affected the viscoelastic behavior of the agar gels less than any other condition studied.

Aging of agar duplicating materials by being reboiled daily appeared to be comparable with aging by storage at $150^{\circ} \mathrm{F}$.

The presence of potassium sulfate or $n$-methyl or $n$-propyl $p$-hydroxybenzoate in concentrations used in agar duplicating materials did not affect the aging characteristics.

The presence of borax in agar duplicating compounds increased the original strength, and the strength remained higher after aging than for agar compounds containing no borax.

Calcium sulfate, as an impurity in agar duplicating compounds, accelerated the degradation of the viscoelastic properties of the gels.

Subdividing agar gels by grinding procedures did not alter the properties unless liquid was lost during the operation.

Ultrasonic treatment of agar sols did not, in general, improve the resistance of the materials to aging as a result of reboiling or storage at elevated temperatures.

\section{REFERENCES}

1. Margetis, P. N., and Hansen, W. C. Changes in Agar-Agar Type Duplicating Material and AgarAgar on Heating and Storage, J.A.D.A., 54:737, 1957.

2. Duke, B. R., and Ryge, G. Properties of Laboratory Duplicating Materials, D. Prog., $1: 88,1961$.

3. Paffenbarger, G. C., Stanrord, J. W., and Sweeney, W. T. American Dental Association Specifications for Dental Materials, 1960-61, p. 44. Chicago: American Dental Association, 1960.

4. Cratg, R. G., and Peyton, F. A. Physical Properties of Elastic Duplicating Materials, J. D. Res., 39:391, 1960 .

5. Wood, E. J. F. Agar in Australia, pp. 1-43. Commonwealth of Australia Council for Scientific and Industrial Research Bull. No. 203, 1946.

6. Pavlov, P. N., and Engelsetern, M. M. Effect of Cations and Anions on the Tensile Strength of Agar and Gelatin, Colloid J. (U.S.S.R.), 2:821, 1936. 